\title{
The influence of motivational factors on ongoing product design decisions
}

DOI:

10.1016/j.jbusres.2020.02.018

\section{Document Version}

Accepted author manuscript

Link to publication record in Manchester Research Explorer

\section{Citation for published version (APA):}

Bleda, M., Querbes, A., \& Healey, M. (2020). The influence of motivational factors on ongoing product design decisions. Journal of Business Research. https://doi.org/10.1016/j.jbusres.2020.02.018

\section{Published in:}

Journal of Business Research

\section{Citing this paper}

Please note that where the full-text provided on Manchester Research Explorer is the Author Accepted Manuscript or Proof version this may differ from the final Published version. If citing, it is advised that you check and use the publisher's definitive version.

\section{General rights}

Copyright and moral rights for the publications made accessible in the Research Explorer are retained by the authors and/or other copyright owners and it is a condition of accessing publications that users recognise and abide by the legal requirements associated with these rights.

\section{Takedown policy}

If you believe that this document breaches copyright please refer to the University of Manchester's Takedown Procedures [http://man.ac.uk/04Y6Bo] or contact uml.scholarlycommunications@manchester.ac.uk providing relevant details, so we can investigate your claim.

\section{OPEN ACCESS}


Business Research

Elsevier Editorial System(tm) for Journal of

Manuscript Draft

Manuscript Number: JBR-D-19-00893R3

Title: The influence of motivational factors on ongoing product design decisions

Article Type: SI: Complexity $C \& O$

Keywords: Complex design, motivation, regulatory focus, customer feedback, NK model

Corresponding Author: Dr. Mercedes Bleda, PhD

Corresponding Author's Institution: University of Manchester

First Author: Mercedes Bleda, PhD

Order of Authors: Mercedes Bleda, PhD; Adrien Querbes; Mark Healey

Manuscript Region of Origin: UNITED KINGDOM

Abstract: Ongoing product design has been defined as a complex problem solving task that is central for the development of new products. Despite its importance, existing work has mostly focused on studying how designers' creativity at the initial stages of design influences the development of radical innovations. However, the role of non-creativity related mechanisms at later stages is still not well understood. Our contribution is to analyze how motivational factors influence noncreative tasks in ongoing incremental design processes. We use an agent based simulation model in which designers improve an existing product by making design modifications based on customers' feedback on product attributes. Drawing on regulatory focus theory, we argue that designers' motivations (promotion focus vs prevention focus) influence the way they search for solutions. We find that, in complex tasks, customer feedback acts as a situational factor that biases designers' decisions, making promotion focused problem-solving more effective than prevention-focused one. 
${ }^{*}$ Detailed Response to Reviewers

Our paper is formatted as per the guidelines of JBR. 
The influence of motivational factors on ongoing product design decisions

Mercedes Bleda, Adrien Querbes, Mark Healey

The University of Manchester

Alliance Manchester Business School

Booth St West, Manchester M15 6PB, United Kingdom

mercedes.bleda@manchester.ac.uk

adrien.querbes@manchester.ac.uk

mark.healey@manchester.ac.uk

Corresponding author: mercedes.bleda@manchester.ac.uk 


\section{The influence of motivational factors on ongoing product design decisions}

Ongoing product design has been defined as a complex problem solving task that is central for the development of new products. Despite its importance, existing work has mostly focused on studying how designers' creativity at the initial stages of design influences the development of radical innovations. However, the role of non-creativity related mechanisms at later stages is still not well understood. Our contribution is to analyze how motivational factors influence non-creative tasks in ongoing incremental design processes. We use an agent based simulation model in which designers improve an existing product by making design modifications based on customers' feedback on product attributes. Drawing on regulatory focus theory, we argue that designers' motivations (promotion focus vs prevention focus) influence the way they search for solutions. We find that, in complex tasks, customer feedback acts as a situational factor that biases designers' decisions, making promotion focused problem-solving more effective than prevention-focused one.

Keywords: Complex product design, motivation, regulatory focus, customer feedback, NK model. 


\section{Introduction}

Product design is a central aspect of new product development processes and innovation (Perks, Cooper, \& Jones, 2005; Roper, Micheli, Love, \& Vahter, 2016). The design of a new product has been conceived as a complex problem-solving task that relies on the mental processes and strategies of designers (Brown, 2008; Liedtka, 2015; Ulrich, 2011). Most research using this conceptualization has focused on understanding the mechanisms that influence the effectiveness of designers' decisions at the initial stages of the innovation process (e.g., Dorst \& Cross, 2001; Kröper, Fay, Lindberg, \& Meinel, 2011; Ward, 2004). Specifically, this research has focused on the mechanisms underpinning the early generation of creative ideas, which can lead to radically new designs and products. In practice, however, many product design decisions concern incremental product modifications aimed at meeting technological requirements and consumer needs that are uncovered as the design process unfolds over time (Eckert, Stacey, Wyatt, \& Garthwaite, 2012; Snider, Dekoninck, \& Culley, 2014). In fact, in many cases the design process is ongoing (Antioco, Moenaert, Lindgreen, \& Wetzels, 2008; Eckert, Clarkson, \& Zanker, 2004; Song and Montoya-Weiss, 1998) in the sense that designers make key enhancements and solve important problems at later stages of the development of a product (Snider, Culley, \& Dekoninck, 2013).

Ongoing design decisions - decisions concerning how to refine and modify the design of a product throughout its life - are crucial for maintaining and enhancing market performance. Evidence shows that many newly developed products fail after initially reaching the market (Antioco et al., 2008; Carbonell, Escudero, \& Aleman, 2004; Cooper, 2001) and that incremental design enhancements can contribute greatly to a product's long-term commercial success (Menguc, Auh, \& Yannopoulos, 2014). For instance, the success of Samsung's Galaxy Note was based on numerous decisions made for each subsequent iteration of the 
device concerning modifications to its various attributes, including display type, charging capability, fingerprint recognition, Wi-Fi, storage capacity, styluses, and more. Ongoing design decisions are particularly important in markets in which changing customer needs or technological advances necessitate almost continuous product development. The continuous modification of product designs presents engineering and organizational challenges (Eckert et al., 2004; Eckert et al., 2012), particularly for complex products involving interdependent attributes (Olausson and Berggren, 2010). Ongoing design is also a cognitively complex task (Simon, 1996) that requires significant information processing, time, and effort (Antioco et al., 2008; Snider, Dekoninck, \& Culley, 2016; Song and Montoya-Weiss, 1998). However, the cognitive challenges associated with making ongoing design modifications to complex products have remained relatively understudied.

In this article we examine the cognitive and motivational processes that underpin decisions concerning ongoing incremental design modifications. Specifically, we posit that for complex products ongoing design decisions reflect the interplay of designers' motivations and cognitive processes. Research shows that motivation exerts a significant influence on product design decisions (Spanjol, Tam, Qualls, \& Bohlmann, 2011), particularly at later stages during which the effect of creativity on design performance tends to decrease (Kröper et al., 2011). As Noble and Kumar (2010) note, "designers can enter a project with one or more dominant motivations that will knowingly or unknowingly guide their work" (p. 652). For instance, in implementing changes in the design of a product, some designers might be motivated to avoid short-term financial losses, while others are motivated to increase longterm adoption rates (Spanjol et al., 2011; Noble \& Kumar, 2010). In a related vein, some designers might be motivated to minimize the utilitarian downsides of a product while others are motivated to improve its hedonic appeal (Chitturi, Raghunathan, \& Mahajn, 2008). In this way, different motivational approaches led to different patterns of decisions. 
We examine designers' motivations based on the principle of regulatory focus (Higgins, 1997), i.e., whether, in making decisions, designers regulate their feelings, thoughts, and actions with a promotion focus or a prevention focus. According to regulatory focus theory (Higgins, 1997; 1998), people adopt basic approach or avoidance strategies based on distinct self-motivational systems which lead to a promotion focus (i.e., striving for gains) or a prevention focus (i.e., avoiding losses). People with different regulatory foci adopt different strategies and behave differently in their attempts to achieve the same goal (Crowe \& Higgins, 1997; Higgins, 1997). Regulatory focus leads to biases in decision making (Cunningham, Raye \& Johnson, 2005; Wang and Lee, 2006; Yoon, Sarial-Abi, \& GürhanCanli, 2012), particularly in complex contexts characterized by high uncertainty and high information load (Ahmadi, Khanagha, Berchicci, \& Jansen, 2017). We draw on these findings to argue that designers approach ongoing complex design problems differently depending on their regulatory focus. Building on the idea that situational factors affect regulatory focus (Förster, Higgins, \& Idson, 1998; Higgins \& Scholer, 2009), and given the importance of customer feedback for product design refinement (Callahan and Lasry, 2004; Song \& Montoya-Weiss, 1998; Carbonell et al., 2004; Zahay, Griffin, \& Fredericks, 2004) we further propose that customers' evaluations of product attributes (Von Hippel, 1988; Franke, von Hippel, \& Schreier, 2006; Fuchs \& Schreier, 2010) act as situational factors which bias designers' decisions.

To investigate how designers' motivations affect ongoing design decisions we use an NK simulation model. Simulation modeling, and specifically the NK model, has been suggested as an appropriate formal way to analyze the dynamics of complex problem-solving processes (Almirall \& Casadesus-Masanell, 2010; Kornish \& Ulrich, 2011; McCarthy et al., 2006; Mihm et al., 2003; Ulrich, 2011). As Ulrich (2011) stated: 
Mathematical models of search have been developed in biology (e.g., Kauffman, 1993) and applied to organizational search [...]. The most popular of these approaches is the NK model. This perspective of search might be productively applied to exploration of concepts in product design. (p. 398)

Accordingly, we use this computational simulation model as a method for theory development (Davis, Eisenhardt, \& Bingham, 2007). Specifically, we represent ongoing design as a problem-solving task in which designers search for new design solutions by implementing incremental changes based on customer feedback about product attributes. In line with regulatory focus theory and regulatory fit, the model shows how different motivational approaches (promotion-focused and prevention-focused) to achieving the same end state (achieving an improved new design solution) lead to different design decisions and long-term performance. The model allows us to analyze performance differences between alternative ongoing design strategies based on promotion and prevention focus. We also compare the effectiveness of these motivationally biased decisions with an unbiased, motivationally-neutral approach. Our simulation results show that motivated search strategies perform better than neutral ones and that for complex products promotion-focused designers find better performing design solutions than those who are prevention focused.

\section{Regulatory focus theory and regulatory fit}

Regulatory focus theory (Crowe \& Higgins, 1997; Higgins, 1997; 1998) postulates that humans are motivated to satisfy the two basic hedonic needs of approaching pleasure and avoiding pain in different ways. When people make decisions towards achieving a goal, they adopt approach and avoidance strategies that derive from two distinct independent motivational systems: a promotion regulatory focus and a prevention regulatory focus 
(Higgins, 1997, 2000). Individuals with a promotion-focused orientation tend to center on hopes, ideals, and aspirations, and are motivated by accomplishments, advancement, and outcomes of gains (desired) or non-gains (undesired). Thus, when pursuing their goals, they tend to disregard potential losses and use eagerness strategies to try to avoid the absence of positive outcomes. Individuals with a prevention-focused orientation tend to center on the fulfilment of duty or responsibility, are concerned with security, safety, and responsibility, and are motivated by outcomes of non-loss (desired) or loss (undesired). They thus use vigilant strategies to try to prevent mistakes, and avoid negative outcomes (Higgins, 2000; Crowe and Higgins, 1997).

Regulatory focus operates as an individual predisposition or chronic orientation that is generally consistent across different situations (Higgins, 1997, 2000). However, since intrinsic motivations are independent from the actual ways in which goals are pursued, people can behave in ways that fit or do not fit their underlying orientation (Scholer \& Higgins, 2008; Higgins \& Scholer, 2009; Johnson, Smith, Wallace, Hill, \& Baron, 2015): individuals modify their behavior to adjust it to contextual factors or cues concerning specific situations (Förster et al., 1998). Thus the way they act may be aligned or unaligned with their chronic regulatory orientation. The alignment of situationally specific behaviors with underlying regulatory focus is termed "regulatory fit" (Higgins, 2000, 2006). Regulatory fit influences the way people select and process information, and this causes biases in their decisionmaking processes. People in general tend to select and rely more on information that is easier to process, i.e., on information that is consistent with their regulatory focus orientation, because processing information that does not "fit" is more difficult and requires more cognitive resources (Yoon et al., 2012). Individuals therefore direct their attention to and place more weight on contextual factors and informational cues that fit their regulatory orientation (Wang \& Lee, 2006). Promotion-focused individuals thus tend to focus more on 
situational positive information while prevention-focused individuals are oriented more on negative information (Pham \& Higgins, 2005; Cunningham et al., 2005). Research has shown that the selective processing of consistent information based on motivational orientation is more likely to occur when information load is high (Fischer et al, 2008; Kardes, Cronley, Kellaris, \& Posavac, 2004). When information load is low, individuals can process inconsistent information more easily (Malhotra, 1982; Yzerbyt \& Demoulin, 2010), and can rely on both on positive and negative signals to make decisions. When information load is high, however, individuals are motivated to reduce the complexity of decision making by relying on a subset of the information that is consistent with their motivational orientation.

In our analysis, customers' evaluations of products' attributes act as situational factors causing biases in the decisions of designers with different motivations. As a result of regulatory fit, promotion-oriented designers focus their attention more on positive customer evaluations (as this information is consistent with their regulatory focus). They tend to overweight the contribution to design performance of positive attributes, and underestimate the effect on performance of negative ones. As a result, in their search for a better design they tend to undertake design refinements that further enhance attributes that are more desirable, functional, or better liked by customers, disregarding the effect that this improvement might have in the performance contribution of negatively perceived ones. In contrast, preventionfocused designers attend more to negative evaluations and overestimate their negative contribution to design performance. Their changes in design thus tend to center on improving or fixing product attributes that customers think do not work or that they dislike. Consistent with regulatory focus theory, while both manage to find improved solutions as design unfolds over time, their behavior and the performance of the final designs they achieve will be different. These biased, hedonically motivated search processes can be compared with an ideal "neutral search" in which designers are able to make unbiased design decisions. 
Designers performing neutral searches are unbiased and are able to process information that is both consistent and inconsistent with their regulatory orientation, i.e., they pay equal attention to, and weight equally, both positive and negative customer informational cues.

To investigate how different motivations lead to differences in design decisions and performance, we build an agent-based simulation model that allows us to investigate which design strategy - improving what works (promotion strategy), or fixing those things that do not work (prevention strategy) - leads to better design solutions.

\section{The model}

We adopted agent-based modeling as our simulation approach because it has been shown to have three key benefits for developing theory on human decision making (e.g. Smith \& Conrey, 2007; Healey, Bleda, \& Querbes, 2018). The first is specificity, as agent-based models allow the flexibility to formally represent any aspect of the decisions that agents take, but also impose a level of control and accuracy in the operationalization of the variables of interest. The second benefit is plausibility, as they allow the incorporation of assumptions about human decision making and behavior based on existing empirical evidence. This is particularly important in emerging theoretical fields where competing novel assumptions have yet to be tested. Third, agent-based models provide insights for theory improvement and internal validation by allowing the researcher to analyze how competing theories and assumptions may or may not achieve empirically relevant results. From an empirical perspective, agent-based simulation modeling and laboratory experiments share many components in their methods. Simulations can be seen as complementing laboratory experiments, by providing tighter control of the experimental conditions and a facilitated monitoring of the variables of interest in inexpensively repeated experiments. 
An agent-based model of ongoing design as a problem-solving task requires two main elements: a representation of the task, i.e., incremental design modifications, and a representation of the potential solutions to the task, i.e. alternative feasible product designs. To represent these two elements, we use an NK model (Kauffman, 1993). The NK model has widely recognized potential to adequately represent problem-solving tasks for the case of complex products and technologies (Kauffman \& Macready, 1995; Ulrich, 2011), as it allows accounting for the effect of interdependencies between the technological or product attributes on their performance and value. ${ }^{1}$ The NK model is particularly apt for capturing the effects of these interdependencies in the case of complex products and technologies in which the performance of a given attribute configuration can exhibit highly nonlinear or non-monotonic behavior in response to changes in one or more of the attributes (Ethiraj \& Levinthal, 2004, p. 161).

In an NK model in which the task is product design, $N$ represents the number of components or attributes of the product, and the parameter $K$ represents the number of interdependencies between these components. With $K=0$, changes in one component do not affect any of the other components, while with $K=N-1$, i.e., for a maximally complex product, each component depends on (and affects) every other. This view on interdependencies in product design can be traced back to Simon (1962), who studied design principles to solve complex problems resulting from complex architectural interactions, and to subsequent work on

\footnotetext{
${ }^{1}$ Several management and innovation scholars following the seminal work by Levinthal (1997) have used the NK-model to represent innovation-related, complex tasks, such as the solving of complex design problems (Baumann \& Siggelkow, 2013; Frenken, Marengo, \& Valente, 1999; Querbes \& Frenken, 2018), new product development processes (Mihm, Loch, \& Huchzermeier, 2003), technological evolution (Frenken, 2007; Querbes \& Frenken, 2017), production techniques (Auerswald, Kauffman, Lobo, \& Shell, 2000), and innovation projects (Sommer \& Loch, 2004).
} 
technological modularity (Baldwin \& Clark, 2000; Ulrich \& Eppinger, 1999) and invention as recombination (Schumpeter, 1939; Nelson \& Winter, 1982). ${ }^{2}$

The multiple combinatorial possibilities achieved by the different variations of the $N$ product attributes generate a landscape of potential product design solutions. In our model, the global performance of each design solution depends on the individual contributions to performance of $N$ product attributes as assessed by customers. This means that not all alternative designs perform equally for customers (who are evaluating them), and so the landscape includes peaks (high performing solutions) and valleys (low performing solutions) and allows comparing the value of alternative design choices on a single scale. We consider that design creates value for customers both through the functions it enables, and the forms it creates (Baldwin \& Clark, 2000). Thus, attributes can be related to functional, symbolic, or aesthetic product features: in their assessment of product design, customers assign value to functional attributes such as "easiness of use", as well as to aesthetic, or symbolic (e.g., visually appealing) features (Rindova \& Petkova, 2007; Burke, 2013).

Each attribute $x_{i}$ can take a value of 0 or 1 ; hence the landscape contains $2^{N}$ alternative solutions. A design solution $x$ is thus represented as $x \in\{0 ; 1\}^{N}$. For instance, if the product is a mobile phone, attribute $x_{1}$ could be "device size", with 0 representing smaller size and 1 representing bigger size; attribute $x_{2}$ could be "battery life", with 0 representing shorter battery life and 1 representing longer battery life; attribute $x_{3}$ could be "internet connection speed", and so on. In the absence of interdependencies between the attributes $(K=0)$ the global performance $F$ of a design solution is given by the average of the attributes' individual contributions:

\footnotetext{
${ }^{2}$ Design Structure Matrices (DSMs) (e.g., MacCormack et al., 2006) have also been used in the NK-model to represent the interdependencies between component technologies from an engineering perspective (Rivkin \& Siggelkow, 2003; Querbes \& Frenken, 2017).
} 


$$
F(x)=\frac{1}{N} \sum_{i=1}^{N} f_{i}\left(x_{i}\right)
$$

where $x_{i}$ is the variant ( 0 or 1$)$ of the individual attribute and $f_{i}\left(x_{i}\right)$-drawn from the random uniform distribution $U(-1,1)$ - is the contribution of this variant to the total performance of the design solution. $f_{i}\left(x_{i}\right) \in[-1,0]$ corresponds to "negative attributes", i.e., attributes that customers evaluate as contributing negatively to performance because they do not like them, they do not work properly, and/or they are not visually appealing. $f_{i}\left(x_{i}\right) \in(0,1]$ denotes the contribution of "positive attributes", i.e. those that customers like, and think work well. In this setting $(K=0)$, a designer can easily find better design solutions by simply finding the highest-performing variant for each product attribute $x_{i}$, which will ultimately lead to the design $x$ with the best performance $F(x)$. For complex products $(K \neq 0)$, however, the contribution of each attribute to total performance $F(x)$ depends on the state of other $K$ attributes. In this case, finding a better design is not such a simple task. For instance, making a product more appealing visually or easier to use by improving the contribution to performance of a particular feature may require a reduction in the performance contribution of other features. In complex product design, designers must make trade-offs focusing on certain attributes in preference to others. For example, Apple's decision to include product features (e.g., internal disk drive and large trackball mouse) to make its "PowerBook" easier to use meant the exclusion of other components to meet size and weight targets (March, 1994). In our example of a mobile phone, finding a better design that involves for instance a longer battery life (change from 0 to 1 in attribute $x_{2}$ ) might entail a bigger device size (change from 0 to 1 in attribute $x_{1}$ ) and hence a reduction in the contribution of $x_{1}$ to the 
performance of the design. ${ }^{3}$ Consequently, for complex products the total performance $F(x)$ of a design solution $x \in\{0 ; 1\}^{N}$ is given by:

$$
F(x)=\frac{1}{N} \sum_{i=1}^{N} f_{i}\left(x_{i} ; x_{i_{1}}, \ldots, x_{i_{K}}\right)
$$

where $x_{i_{1}}, \ldots, x_{i_{K}}$ are the $\mathrm{K}$ components influencing the contribution of the component $x_{i}$, and $f_{i}$ now takes $2^{K+1}$ values drawn from the random uniform distribution in $[-1,1]$.

An optimal strategy to solve a complex design task as defined above would require complete knowledge of the entire solutions landscape, including knowing the best-performing design solution. However, knowing this exponentially high number of alternatives is at odds with human limitations in information gathering and processing. In our model, designers are bounded rational (Simon, 1976) and search the landscape following heuristics, i.e., using simple rules that guide the exploration of a subset of alternative design solutions (Gigerenzer, Todd, \& The ABC Research Group, 1999). Our simple rule is hill-climbing; that is, a new solution is chosen if it involves an increase in the design performance, and since our task is ongoing design, our search is local, meaning that designers search in a subset of adjacent or close alternatives (Fleming, 2001), i.e., they search by modifying one product attribute at a time, and then select the resultant alternative adjacent solution that offers the highest performance improvement. If no alternative solution provides an improvement, they stop

\footnotetext{
${ }^{3}$ Complexity can be tuned via the ratio $K / N$, with higher complexity making it more difficult to find higher performing design solutions or peaks. Complexity also makes it more difficult to maintain total performance in the local vicinity of potential alternative solutions, which means that discarding design solutions with badly performing attributes becomes increasingly difficult (Frenken et al., 1999). Therefore, while a high number of attribute interdependencies increases the potential for synergies among them, and hence for increased solution performance, these synergies can be offset by conflicts or trade-offs in detriment of solution performance (Ulrich, 1995; Fleming \& Sorenson, 2001).
} 
searching. Searching thus always ends on a design solution for which no close solution provides a design with better performance.

In the model, this cognitive process of refinement or incremental search occurs in a landscape of design solutions that is completely exogenous (Ganco, 2017). In other words, we are assuming that customers' preferences and the mental schema they use to assign value remain stable over the simulation period. This is consistent with the idea that customers' assessments of the contributions of products' attributes to performance are based on preexisting and unchanging preferences (Ramirez, 1999). It is also consistent with studies that propose that customers' evaluations are influenced by generic mental schema that can change when product design modifications are radical, but which remain unchanged for incremental changes. For incremental design refinements, customers tend to use the same generic schema to assign value (Rindova \& Petkova, 2007). In our case, as ongoing design involves incremental changes, we can assume that customers' generic schemas are stable over the simulation period.

As previously discussed, in our work, we assume that the decisions of designers with different underlying motivations or regulatory foci are biased by customer evaluations acting as situational factors. The influence that biases have on decision-making effectiveness in complex tasks has already been incorporated in previous formal models (e.g. Kauffman \& Macready, 1995; Levitan \& Kauffman, 1995; Macready, Siapas, \& Kauffman, 1996) and in models of managerial, bounded, rational decision making (e.g., Knudsen \& Levinthal, 2007; Baumann \& Martignoni, 2011). These models study how random biases in the way agents perceive and evaluate the global performance of solutions (e.g. new products, technologies) affect the effectiveness and the stability of search processes (e.g., Rivkin \& Siggelkow, 2003). Our modeling approach differs from this previous work in two respects. First, our biases are not randomly created but driven by the agents'/designers' motivational orientation 
and situational factors (customer feedback). Second, in our model cognitive biases affect the effectiveness of the decisions by operating on the designers' perceptions and processing of information on individual solution components (feedback on product attributes), rather than on their perception of the global performance of a solution. Both contributions allow our model to provide a more nuanced and plausible account of how motivation and information processing affect the performance of a complex task.

As also previously discussed, in our model prevention-focused product designers try to achieve better designs by performing what we call a "negative search" in which they overweight the individual contribution of "negative" product attributes (those which, according to customers' evaluations, contribute negatively to global design performance) and underweight those which contribute to performance in a positive way ("positive attributes"). Promotion-focused designers perform a "positive search": they overweight the contribution of positive attributes and underweight that of negative ones. The global performance of a design solution thus becomes a weighted average of the product attributes' contributions as follows:

$$
F_{\text {hedonic }}=\frac{1}{N}\left(\alpha \sum f_{i}^{+}+\beta \sum f_{i}^{-}\right)
$$

where $f_{i}^{+}$represents the contribution to performance of positive attributes $\left(f_{i}>0\right)$, and $f_{i}^{-}$ represents the contribution of negative ones $\left(f_{i}<0\right)$.

The weights $\alpha$ and $\beta$ allow us to represent how the magnitude of the motivational biases influences the global performance of a given design solution by modifying (underweighting and overweighing) the values of $f_{i}^{+}$and $f_{i}^{-}$. With $\alpha=\beta=1$, equation (3) becomes (2)s which corresponds to a neutral search in which designers process negative and positive 
customer evaluations in the same way (and $f_{i}^{+}$and $f_{i}^{-}$values hence remain unaltered). In a positive search, the values $f_{i}^{+}$are overestimated and $f_{i}^{-}$are discounted with magnitudes for $\alpha \in(1,2]$ and $\beta=2-\alpha$. The opposite holds for a negative search in which $\beta \in(1,2]$ and $\alpha=2-\beta$. The magnitude of the biases depends on the values of $\alpha$ and $\beta$, which reflect the designer's focus when processing the valence of customer feedback. At each time step, designers receive customer feedback on the products attributes and proceed to look for refinements in the existing design solution based on this information. To compare hedonic ongoing design search with a neutral search, we run simulations for neutral search and for the full range of weights magnitudes of $\alpha$ and $\beta$ on an NK landscape of design solutions with $N=20$ components and $K=4$ (other values of $N$ and $K$ have been tested and produced the same results qualitatively). To control for the stochasticity of the landscapes, we repeated our simulations over 10,000 landscapes, so all our results show the average of the values collected in these 10,000 landscapes. To avoid unnecessary noise, all types of search always start from the same solution design of the landscape.

\section{Results and discussion}

The results of our simulation model are shown in Figure 1. Figure 1 shows the final design performance of neutral and hedonic search for all the values of the parameters $\alpha$ and $\beta$. Our first key result is that for complex products, prevention-focused designers undertaking negative searches always perform worse than neutral searches in the long run. This is the case for any intensity of the motivational bias, i.e., for any value of $\beta>1$. In contrast, positive searches performed by promotion-focused designers perform significantly better than both negative searches and neutral searches, even for low values of $\alpha$ (with $\alpha$ as low as 1.05). As the value of $\alpha$ increases, however, positive searches lose their advantage (around $\alpha=1.5$ ) and are outperformed by neutral searches. 
The existence of this threshold is similar to the threshold found in studies dealing with dispositional optimism in problem solving (the tendency to expect positive outcomes even when such expectations are not rationally justified): a moderately high level of optimism improves performance, but only up to a point, beyond which a higher level of optimism actually decreases performance. For instance, in their study on optimism and entrepreneurship, Hmieleski and Baron (2009) found that, while a moderate level of optimism improves the performance of entrepreneurial tasks, for very high levels of optimism there is a negative relationship between entrepreneurs' optimism and new venture performance.

\#\# Figure 1 about here \#\#

Our simulation results also show that similar motivational biases affecting the different valences of feedback (customer liking versus disliking product attributes) influence final design performance in very different ways. In the example shown in Figure 1, the same magnitude of 1.25 applied to a negative search $(\beta=1.25)$ or a positive search $(\alpha=1.25)$ produces highly contrasted long-term results, with a final performance of 0.42 for the negative search (significantly below the unbiased neutral search), and over 0.43 for the positive search (significantly above the unbiased neutral search). This highlights that the valence of the feedback (i.e., positive versus negative) plays a more significant role in the performance of the task design than the intensity or magnitude of the motivational bias it creates. This is consistent with evidence showing that motivational biases have asymmetric effects in information evaluation and decision-making performance (Spanjol et al., 2011; Noble \& Kumar, 2010). 
The differences in search paths are illustrated in Figure 2, which represents examples of a neutral search $(\alpha=\beta=1)$, a negative search $(\alpha=0.75 ; \beta=1.25)$, and a positive search $(\alpha=1.25 ; \beta=0.75)$. As the figure shows, almost from the start, different motivations and regulatory fit lead designers to adopt different strategies and find improved solution designs that, even when they are similar in performance, involve very different configurations of product attributes. The figure also illustrates that, although incremental design modifications always lead to better performing solutions, neutral searches perform better at the beginning of the simulation; however, halfway through they are outperformed by positive searches. Promotion focus thus makes positive searches more effective and allows designers to find better performing designs than neutral and negative searches.

\#\# Figure 2 about here \#\#

Looking at the different paths followed in each type of search provides a better understanding of the source of the performance advantage achieved by a promotion focused regulatory focus. Existing models of problem-solving tasks incorporating biased searches (e.g., Knudsen \& Levinthal, 2007; Baumann \& Martignoni, 2011) have shown that biases provide an advantage over unbiased neutral searches by allowing agents to avoid getting locked in or stuck with solutions that are good but not the best ones. This gives them more stimulus to explore the search space for longer, increasing the likelihood of them finding more distant and possibly better solutions. In our ongoing design task, this would be equivalent to saying that in positive searches designers search for longer than in neutral searches, which allows them to find better performing design solutions. However, in our model, the advantage conferred by a promotion-focused orientation is not due to a longer exploration path. As the 
bottom panel in Figure 1 shows, a promotion focus does not increase the duration of the search. In fact, designers achieve better performing designs after a relatively low number of incremental design refinements. In addition, despite the existence of a positive correlation between the ability to explore more design options and the achievement of a higher final performance (in particular for negative searches), the highest value for final performance ( $\alpha \approx 1.25$ ) does not correspond with the highest number of design refinements, i.e., searching for longer does not necessarily lead to the best-performing solution.

As Figure 2 shows, at the beginning of the search process, positive search follows a decisions path that diverges quite markedly from the path followed by neutral search. Our results suggest that promotion-focused designers find and take a design path that neither unbiased nor prevention-focused designers are able to discover. At the beginning of this path, product design performance improvements (resulting from enhancements of positive attributes) are less rewarding than those carried out by neutral search, in which designers take more balanced (unbiased) design decisions that initially provide better global performance gains (as seen in Figure 2). However, the design choices taken by promotion-focused designers in the short run increase the future availability of better designs - designs that neutral designers, already embarked in a currently more rewarding path, and prevention-focused designers do not discover. Consequently, a promotion-focused orientation makes searching more effective towards the end, by increasing the performance of late-ongoing design decisions: motivational biases help designers to find a specific path that, although not very rewarding initially, leads them to better-performing design solutions in the long run.

\section{Conclusions}

Research has proposed that designers' motivation is an important determinant of effective design decisions (Noble \& Kumar, 2010) and a critical antecedent to achieving high performing designs (Kröper et al., 2011). Our work extends our understanding of the role of 
motivational factors in ongoing design, by showing how designers' intrinsic motivations (regulatory focus) and the cognitive biases they create through regulatory fit influence their behavior and the performance of their decisions over time. According to our analysis, designers who are motivated by the accomplishment of a successful new design, rather than seeing the task as a managerial responsibility to fulfil, achieve better designs. This motivation makes them focus on improving product attributes that are highly valued by customers and disregard any damaging effect that this may have on the rest of the attributes, and hence on the overall design.

Rindova and Petkova (2007) proposed that customers' assessments of a new product value are based on the specific configuration of the entire set of the product's attributes, and that the value of the product thus depends on if and how this set makes sense "as a whole". Studies have also posited that this holistic evaluation depends on the various trade-offs that consumers make among the different attributes of a product: consumers use the attributes of a product to determine its overall value, but they tend to place more value on certain attributes or features (Burke, 2013) and forego some features to obtain others (Fishbein and Ajzen, 1975). For instance, research on the influence of specific design dimensions on product value has shown that consumers tend to value products that communicate ergonomic features such as "easiness of use" (Creusen \& Schoormans, 2005), and that they tend to have a preference for usability attributes over other functional features and price (Burke, 2013). Symbolic and aesthetic attributes have also been highlighted as having a significant role in the overall evaluation that consumers make of a product. For instance, the iMac, introduced by Apple in 1998, incorporated relatively minor technological improvements; however its fruitlike colors and shapes made it acclaimed as "the coolest personal computer on the planet" (Needham, 2002, p. 10) and it became the best-selling computer in Apple's history (Yoffie \& Kwak, 1999; Rindova \& Petkova, 2007). Another example that illustrates how certain specific 
attributes may contribute to the commercial success of a product is the design of the Mini Cooper. As one commentator observed: "Whatever one may think of the Mini Cooper's dynamic attributes, which range from very good to marginal, it is fair to say that almost no new vehicle in recent memory has provoked more smiles" (Swan, 2002, p. 1). In this case, the Mini Cooper's aesthetic properties may have overridden more objective assessments of its functional attributes, leading to an enhanced overall perception of its value, as illustrated by the high demand the vehicle generated (Rindova \& Petkova, 2007).

According to our study, promotion-focused regulatory orientation favors design refinements that further enhance salient products attributes that customers value the most, achieving design solutions that will perform better overall. In our analysis, this overestimation is unintentional as it is driven by motivational biases in the processing of customer feedback, i.e., it is an imperfect evaluation of customers' information, rather than a conscious strategic decision to satisfice them, that leads to better designs. In this sense, our work suggests that motivational factors may have strategic value for an organization, and that excitement and eagerness in ongoing design pay off. By studying the role of motivation in ongoing product design, we add to existing research in three main ways.

First, our analysis extends the predominantly cognitive approach to complex design decisions to include the effects of motivation (Ahmadi et al., 2017; Hodgkinson and Healey, 2011). Existing work tends to assume that cognitive capacity is the primary constraint on the ability to solve complex design problems (Simon, 1976; Eckert et al., 2004, 2012). In contrast, our findings suggest that motivational orientation is important for solving such problems, not least because it shapes the focus of ongoing design decisions. Our findings also have implications for research on cognitive biases in design decisions. Much of this research has focused on eradicating cognitive biases based on the assumption that they hinder performance (Antioco, et al., 2008; Liedtka, 2015). Our results confirm that some biases undermine design 
decisions but also draw attention to the potential functional benefits of other types of motivational and cognitive bias.

Second, we provide a new take on the idea that cognitive challenges are most influential at the early, creative stages of design (Dorst \& Cross, 2001; Kröper et al., 2011). We suggest that motivation is a more pervasive and continual influence on design decision making, pointing the way for future research that broadens our understanding of motivational influences throughout product development.

Third, our work draws attention to motivational sources of heterogeneity in the technological discovery process. In this respect, it can be argued that intra-industry heterogeneity could be partly explained by differences between the search strategies and decisions of promotionoriented designers and those of prevention-oriented ones. For instance, in the robotics industry companies tend to follow different innovation paths (see, e.g., Katila and Ahuja, 2002). In light of our analysis this may be explained by arguing that some use strategies aimed at eradicating or improving features that cause moral or safety concerns (a prevention focus), while others aim at augmenting or developing the advantageous features of robotics. Manufacturing industries characterized by differences in the sustainability orientations of their companies would be another example, in which intra-industry heterogeneity may be partly explained by differences between the strategies of promotion-oriented companies (motivated by the improvement of products' functional performance) and those of prevention-oriented ones (e.g. more sustainability-oriented companies) more focused on the improvement of products' sustainability performance.

Designers usually work and search for new designs as part of a team. Our analysis does not incorporate the influence of this interaction. However, to understand how motivational factors affect collective design decision making, it is first desirable and necessary to 
understand individual intrinsic motivations. Understanding collective phenomena often requires first understanding building blocks at the individual level, including decision making and problem solving (see, e.g., Felin, Foss, Heimeriks, \& Madsen, 2012). Therefore, our analysis provides a first step and a platform for future research to extend the analysis to investigate the role of motivational factors at the group level. In addition, since our analysis is essentially conceptual, an additional extension of our work is to gather data through behavioral experiments in order to empirically validate our key results. Billinger, Stieglitz and Schumacher (2014) recently demonstrated the utility of this approach to validating the findings of computational experiments. Their work focused on exploration strategies related to the overall performance levels of products. Our work could inform similar behavioral experiments to analyze how designers process more detailed feedback on individual product attributes, and how this affects the performance of the final design. 


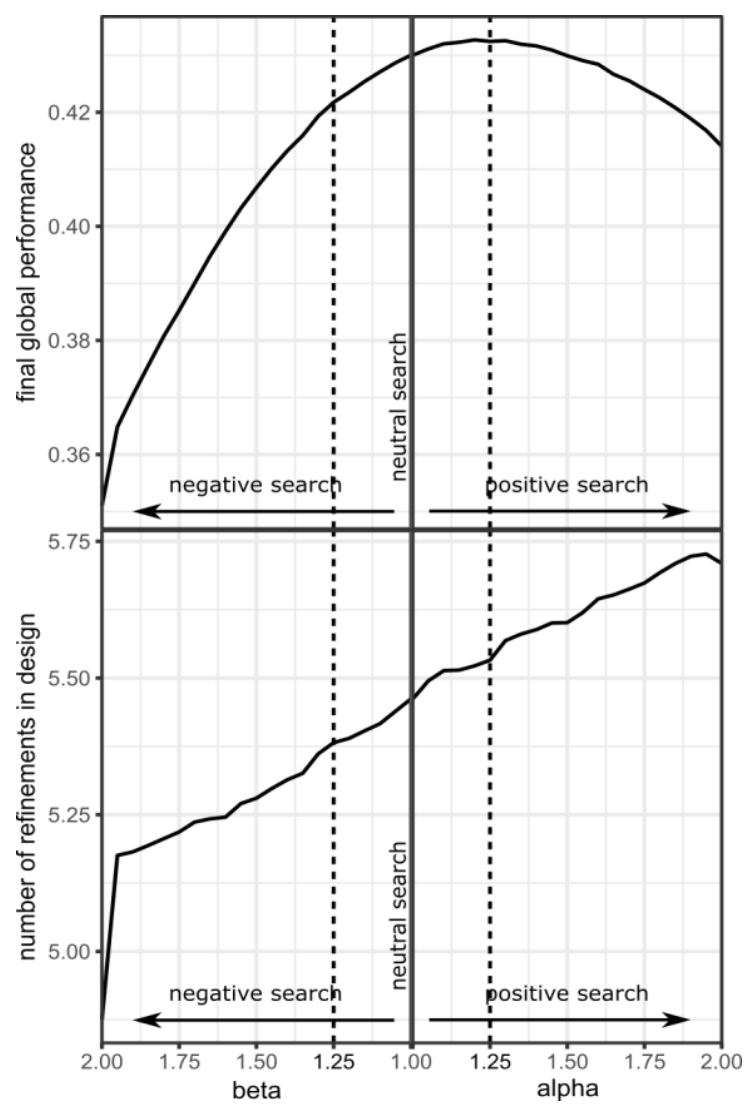

Figure 1 Search performance and length

Top panel: Search performance. Performance is measured for all weight values of $\alpha$ and $\beta$ in the range [1,2] and using final global performance as defined in equations 2 and 3 , after the search has stopped, i.e., when none of the adjacent solutions involves improvement in design.

Bottom panel: Search path length. 


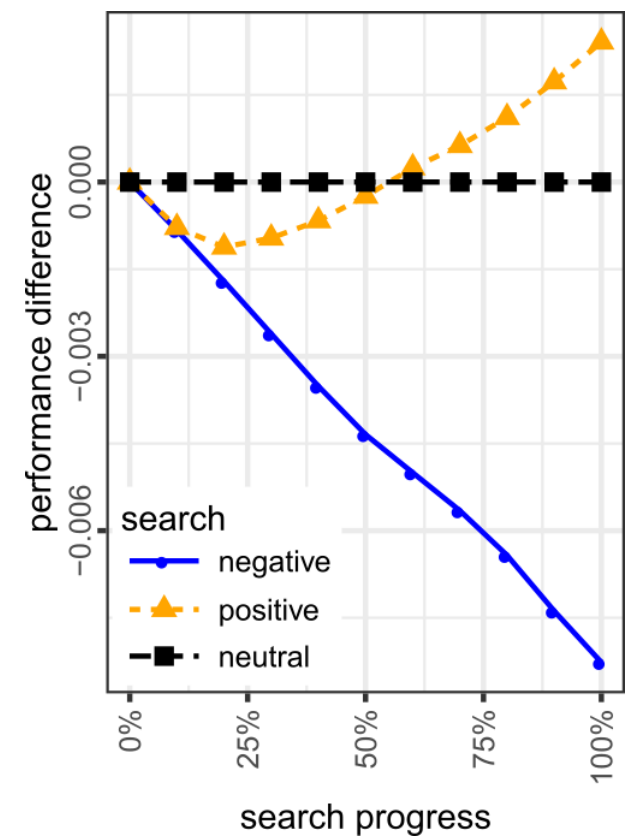

Figure 2: Search path

Search performance is measured at each time step after every design refinement. The graph reports the difference of performance between neutral search $(\alpha=\beta=1)$ and one example of negative search $(\alpha=0.75 ; \beta=1.25)$ and positive search $(\alpha=1.25 ; \beta=0.75)$. 


\section{References:}

Ahmadi, S., Khanagha, S., Berchicci, L., and Jansen, J. J. (2017). Are managers motivated to explore in the face of a new technological change? The role of regulatory focus, fit, and complexity of decision-making. Journal of Management Studies, 54(2), 209-237.

Almirall, E., and Casadesus-Masanell, R. (2010). Open versus closed innovation: A model of discovery and divergence. Academy of Management Review, 35(1), 27-47.

Antioco, M., Moenaert, R. K., Lindgreen, A., and Wetzels, M.G. (2008). Organizational antecedents to and consequences of service business orientations in manufacturing companies. Journal of the Academy of Marketing Science, 36(3), 337-358.

Antioco, M., Moenaert, R.K. and Lindgreen, A. (2008). Reducing ongoing product design decision making bias. Journal of Product Innovation Management, 25(6), 528-545.

Auerswald, P., Kauffman, S., Lobo, J., and Shell, K. (2000). The production recipes approach to modeling technological innovation: An application to learning by doing. Journal of Economic Dynamics and Control, 24(3), 389-450.

Baldwin, C. Y., and Clark, K. B. (2000). Design rules: The power of modularity (Vol. 1). MIT Press.

Baumann, O., and Martignoni, D. (2011). Evaluating the new: the contingent value of a proinnovation bias. Schmalenbach Business Review, 63(4), 393-415.

Baumann, O., and Siggelkow, N. (2013). Dealing with complexity: Integrated vs. chunky search processes. Organization Science, 24(1), 116-132.

Billinger, S., Stieglitz, N., and Schumacher, T. R. (2014). Search on rugged landscapes: An experimental study. Organization Science, 25(1), 93-108.

Brown, T. (2008). Design thinking. Harvard Business Review, 86(6), 84-92.

Burke, P.F. (2013). Seeking simplicity in complexity: The relative value of ease of use (EOU)- based product differentiation. Journal of Product Innovation Management, 30(6), 1227-1241.

Callahan, J., and Lasry, E. (2004). The importance of customer input in the development of very new products. $R \& D$ Management, $34(2), 107-120$.

Carbonell, P., Escudero, A. I. R., and Aleman, J. L. M. (2004). Technology newness and impact of go/no-go criteria on new product success. Marketing Letters, 15(2-3), 81-97.

Cooper, R. G. (2001). Winning at New Products: Accelerating the Process from Idea to Launch (3rd ed.). New York: Basic Books.

Creusen, M. E. and Schoormans, J. P. (2005). The different roles of product appearance in consumer choice. Journal of Product Innovation Management, 22(1),63-81.

Crowe, E. and Higgins, E. T. (1997). Regulatory focus and strategic inclinations: Promotion and prevention in decision-making. Organizational Behavior and Human Decision Processes, 69(2), 117-132.

Cunningham, W. A., Raye, C. L., and Johnson, M. K. (2005). Neural correlates of evaluation associated with promotion and prevention regulatory focus. Cognitive, Affective, \& Behavioral Neuroscience, 5(2), 202-211.

Davis, J. P., Eisenhardt, K. M., and Bingham, C. B. (2007). Developing theory through simulation methods. Academy of Management Review, 32(2), 480-499.

Dorst, K. and Cross, N. (2001). Creativity in the design process: co-evolution of problemsolution. Design studies, 22(5), 425-437.

Eckert, C., Clarkson, P. J., and Zanker, W. (2004). Change and customisation in complex engineering domains. Research in Engineering Design, 15(1), 1-21.

Eckert, C., Stacey, M., Wyatt, D., and Garthwaite, P., 2012. Change as little as possible: creativity in design by modification. Journal of Engineering Design, 23(4), 337-360.

Ethiraj, S. K., and Levinthal, D. (2004). Modularity and innovation in complex systems. Management science, 50(2), 159-173. 
Felin, T., Foss, N. J., Heimeriks, K. H., and Madsen, T. L. (2012). Microfoundations of routines and capabilities: Individuals, processes, and structure. Journal of Management Studies, 49(8), 1351-1374.

Fischer, P., Schulz-Hardt, S., and Frey, D. (2008). Selective exposure and information quantity: how different information quantities moderate decision makers' preference for consistent and inconsistent information. Journal of Personality and Social Psychology, 94(2), 231.

Fishbein M., and Ajzen, I. (1975). Belief, Attitude, Intention and Behavior: An Introduction to Theory and Research. Reading, MA: Addison-Wesley.

Fleming, L. (2001). Recombinant uncertainty in technological search. Management Science, 47(1), 117-132.

Fleming, L., and Sorenson, O. (2001). Technology as a complex adaptive system: evidence from patent data. Research Policy, 30(7), 1019-1039.

Förster, J., Higgins, E. T., and Idson, L. C. (1998). Approach and avoidance strength during goal attainment: regulatory focus and the "goal looms larger" effect. Journal of Personality and Social Psychology, 75(5), 1115.

Franke, N., von Hippel, E., and Schreier, M. (2006). Finding commercially attractive user innovations: A test of lead-user theory. Journal of Product Innovation Management, 23(4), 301-315.

Frenken, K. (2007). Innovation, Evolution and Complexity Theory. Cheltenham: Edward Elgar.

Frenken, K., Marengo, L., and Valente, M. (1999). Interdependencies, nearlydecomposability and adaptation. In Brenner, T. (Ed.), Computational techniques for modelling learning in economics (145-165). Boston, MA: Springer.

Fuchs, C. and Schreier, M. (2010). Customer Empowerment in New Product Development. Journal of Product Innovation Management, 1(28), 17-32.

Ganco, M. (2017). NK model as a representation of innovative search. Research Policy, 46(10), 1783-1800.

Gigerenzer, G., Todd, P. M., and The ABC Research Group. (1999). Simple Heuristics That Make Us Smart. Oxford: Oxford University Press.

Healey M., Bleda M., and Querbes A. (2018). Modeling affect and cognition: opportunities and challenges for managerial and organizational cognition. In Galavan R. J., Sund K. J., and Hodgkinson G. P. (Eds.), Methodological Challenges and Advances in Managerial and Organizational Cognition (New Horizons in Managerial and Organizational Cognition, Volume 2), 23-57. Bingley, West Yorkshire: Emerald Publishing Limited.

Higgins, E. T. (1997). Beyond pleasure and pain. American Psychologist, 52(12), 1280.

Higgins, E. T. (1998). Promotion and prevention: Regulatory focus as a motivational principle. Advances in Experimental Social Psychology, 30, 1-46

Higgins, E. T. (2000). Making a good decision: value from fit. American psychologist, $55(11), 1217$.

Higgins, E. T. (2006). Value from hedonic experience and engagement. Psychological Review, 113(3), 439.

Higgins, E. T. and Scholer, A. A. (2009). Engaging the consumer: The science and art of the value creation process. Journal of Consumer Psychology, 19(2), 100-114.

Hmieleski, K. M., and Baron, R. A. (2009). Entrepreneurs' optimism and new venture performance: A social cognitive perspective. Academy of Management Journal, 52(3), 473-488.

Hodgkinson, G. P., and Healey, M. P. (2011). Psychological foundations of dynamic capabilities: Reflexion and reflection in strategic management. Strategic Management Journal, 32(13), 1500-1516. 
Johnson, P. D., Smith, M. B., Wallace, J. C., Hill, A .D., and Baron, R. A. (2015). A review of multilevel regulatory focus in organizations. Journal of Management, 41(5), 15011529.

Kardes, F. R., Cronley, M. L., Kellaris, J. J., and Posavac, S. S. (2004). The role of selective information processing in price-quality inference. Journal of Consumer Research, $31(2), 368-374$.

Katila, R., \& Ahuja, G. (2002). Something old, something new: A longitudinal study of search behavior and new product introduction. Academy of Management Journal, 45(6), 1183-1194.

Kauffman, S. A. (1993). The Origins of Order. New York: Oxford University Press.

Kauffman, S., and Macready, W. (1995). Technological evolution and adaptive organizations: Ideas from biology may find applications in economics. Complexity, $1(2), 26-43$.

Knudsen, T., and Levinthal, D. A. (2007). Two faces of search: Alternative generation and alternative evaluation. Organization Science, 18(1), 39-54.

Kornish, L. J., and Ulrich, K. T. (2011). Opportunity spaces in innovation: Empirical analysis of large samples of ideas. Management Science, 57(1), 107-128.

Kröper, M., Fay, D., Lindberg, T., and Meinel, C. (2011). Interrelations between motivation, creativity and emotions in design thinking processes-An empirical study based on regulatory focus theory. In Taura, T. and Nagai, Y. (Eds.), Design creativity, 97-104. London: Springer.

Levinthal, D. A. (1997). Adaptation on rugged landscapes. Management Science, 43(7), 934950.

Levitan, B., and Kauffman, S. (1995). Adaptive walks with noisy fitness measurements. Molecular Diversity, 1(1), 53-68.

Liedtka, J. (2015). Perspective: Linking design thinking with innovation outcomes through cognitive bias reduction. Journal of Product Innovation Management, 32(6), 925-938.

Macready, W. G., Siapas, A. G., and Kauffman, S. A. (1996). Criticality and parallelism in combinatorial optimization. Science, 271(5245), 56-59.

Malhotra, N. K. (1982). Multi-stage information processing behavior: An experimental investigation. Journal of the Academy of Marketing Science, 10(1), 54-71.

March, J. G. (1994). Primer on decision making: How decisions happen. New York: Simon and Schuster.

Mihm, J., Loch, C., and Huchzermeier, A. (2003). Problem-solving oscillations in complex engineering projects. Management Science, 49(6), 733-750.

Needham, S. (2002). Design choice: Apple iMac. Marketing (July 4) 10.

Nelson, R. R. and Winter, S. G. (1982). An Evolutionary Theory of Economic Change. Cambridge: Belknap Press.

Noble, C. H. and Kumar, M. (2010). Exploring the appeal of product design: A grounded, value-based model of key design elements and relationships. Journal of Product Innovation Management, 27(5), 640-657.

Olausson, D. and Berggren, C. (2010). Managing uncertain, complex product development in high-tech firms: in search of controlled flexibility. $R$ and $D$ Management, 40(4), 383399.

Perks, H., Cooper, R., and Jones, C. (2005). Characterizing the role of design in new product development: An empirically derived taxonomy. Journal of Product Innovation Management, 22(2), 111-127.

Pham, M. T. and Higgins, E. T. (2005). Promotion and prevention in consumer decisionmaking: The state of the art and theoretical propositions. In S. Ratneshwar and D. g. Mick (Eds.), Inside Consumption: Consumer Motives, Goals, and Desires, 30-65. Oxford: Routledge. 
Querbes, A., and Frenken, K. (2017). Evolving user needs and late-mover advantage. Strategic Organization, 15(1), 67-90.

Querbes, A., and Frenken, K. (2018). Grounding the "mirroring hypothesis": Towards a general theory of organization design in New Product Development. Journal of Engineering and Technology Management, 47, 81-95.

Rindova, V. P. and Petkova, A. P. (2007). When is a new thing a good thing? Technological change, product form design, and perceptions of value for product innovations. Organization Science, 18(2), 217-232.

Rivkin, J. W., and Siggelkow, N. (2003). Balancing search and stability: Interdependencies among elements of organizational design. Management Science, 49(3), 290-311.

Roper, S., Micheli, P., Love, J. H. and Vahter, P. (2016). The roles and effectiveness of design in new product development: A study of Irish manufacturers. Research Policy, 45(1), 319-329.

Scholer, A. A. and Higgins, E. T. (2008). Distinguishing levels of approach and avoidance: An analysis using regulatory focus theory. In A. J. Elliot (Ed.), Handbook of approach and avoidance motivation, 489-503. New York: Psychology Press.

Schumpeter, J. (1939). Business Cycles. New York: McGraw-Hill.

Simon, H. A. (1962). The architecture of complexity. Proceedings of the American Philosophical Society, 106(6), 467-482.

Simon, H.A., 1976. Administrative Behavior (3rd ed.). Oxford: Simon and Schuster.

Simon, H.A., 1996. The Sciences of the Artificial (3rd ed.). Cambridge, MA: MIT Press.

Smith, E. R. and Conrey, F. R. (2007). Agent-Based Modeling: A New Approach for Theory Building in Social Psychology, Personality and Social Psychology Review, 11, 87.

Snider, C.M., Culley, S.J. and Dekoninck, E.A., 2013. Analysing creative behaviour in the later stage design process. Design Studies, 34(5), 543-574.

Snider, C. M., Dekoninck, E. A., and Culley, S. J. (2014). The appearance of creative behavior in later stage design processes. International Journal of Design Creativity and Innovation, 2(1), 1-19.

Snider, C., Dekoninck, E., and Culley, S. (2016). Beyond the concept: characterisations of later-stage creative behaviour in design. Research in Engineering Design, 27(3), 265289.

Sommer, S. C., and Loch, C. H. (2004). Selectionism and learning in projects with complexity and unforeseeable uncertainty. Management Science, 50(10), 1334-1347.

Song, X. M. and Montoya-Weiss, M. M. (1998). Critical development activities for really new versus incremental products. Journal of Product Innovation Management, 15(2), 124-135.

Spanjol, J., Tam, L., Qualls, W. J., and Bohlmann, J. D. (2011). New product team decision making: Regulatory focus effects on number, type, and timing decisions. Journal of Product Innovation Management, 28(5), 623-640.

Swan, T. (2002). Behind the wheel / Mini Cooper. New York Times, June 2.

Ulrich, K. T. (1995). "The role of Product Architecture in the Manufacturing Firm. Research Policy, 24 (3), 419-440.

Ulrich, K. T., (2011). Design is everything? Journal of Product Innovation Management, 28(3), 394-398.

Ulrich, K. T. and Eppinger S. D. (1999). Product design and development (2nd ed.). New York: McGraw-Hill.

Von Hippel, E. (1988). The Sources of Innovation. New York: Oxford University Press.

Wang, J. and Lee, A. Y. (2006). The role of regulatory focus in preference construction. Journal of Marketing Research, 43(1), 28-38.

Ward, T. B. (2004). Cognition, creativity, and entrepreneurship. Journal of Business Venturing, 19(2), 173-188. 
Yoffie, D. B., and Kwak, M. (1999). Apple Computer 1999. Harvard Business School Case, 799-108.

Yoon, Y., Sarial-Abi, G., and Gürhan-Canli, Z. (2012). Effect of regulatory focus on selective information processing. Journal of Consumer Research, 39(1), 93-110.

Yzerbyt, V. and Demoulin, S. (2010). Intergroup relations. Handbook of Social Psychology, $2,1024-1083$. 